\title{
Fetal therapies as standard prenatal care in Japan
}

\author{
Haruhiko Sago, MD, PhD, Seiji Wada, MD, PhD \\ Center for Maternal-Fetal, Neonatal and Reproductive Medicine, National Center for Child Health and Development, Tokyo, Japan
}

With recent advances in fetal medicine, various attempts have been made to save fetuses facing perinatal death or devastating consequences despite optimal management after birth. The concept of the fetus as a patient has been established through the application of in utero treatments. This paper reviews fetal therapies in order to highlight the role of perinatal medicine as standard prenatal care. Fetal therapies consist of medical therapy, percutaneous ultrasound-guided surgery, fetoscopic surgery, and open fetal surgery. In the 1980s, with advances in ultrasound imaging, percutaneous ultrasound-guided surgeries such as vesicoamniotic shunting for lower urinary tract obstruction and thoracoamniotic shunting (TAS) for fetal hydrothorax (FHT) were started. In the 1990s, fetoscopic laser surgery (FLS) for twin-twin transfusion syndrome (TTTS) was introduced, and later, a fetoscopic approach for congenital diaphragmatic hernia was also established. The revival of open fetal surgery, introduced in the 1980s by pediatric surgeons, began in the 2010s after a successful clinical study for myelomeningocele. Although many fetal therapies are still considered experimental, some have proven effective, such as FLS for TTTS, TAS for primary FHT, and radiofrequency ablation (RFA) for twin reversed arterial perfusion (TRAP) sequence. These three fetal therapies have been approved for coverage by Japan National Health Insurance as a result of clinical studies performed in Japan. FLS for TTTS, TAS for primary FHT, and RFA for TRAP sequence have become standard prenatal care approaches in Japan. These three minimally invasive fetal therapies will help improve the perinatal outcomes of fetuses with these disorders.

Keywords: Fetoscopy; Fetal therapy; Fetofetal transfusion; Radiofrequency therapy; Ultrasonogaphy

\section{Introduction}

With recent advances in fetal medicine, the concept of the fetus as a patient has led to the application of treatments in utero. The aim of fetal therapy is to save fetuses who are facing perinatal death or devastating consequences despite optimal management after birth. The first fetal intrauterine blood transfusion, performed in the early 1960s, is thought to mark the beginning of fetal therapy [1]. The milestones of fetal surgical therapy are shown in Table 1 . With advances in ultrasound imaging in the 1980s, fetal blood transfusion [2], vesicoamniotic shunting for lower urinary tract obstruction (LUTO) [3], and thoracoamniotic shunting (TAS) for hydrothorax [4] were performed with ultrasound guidance. Pediatric surgeons at the University of California at San Francisco (UCSF) introduced open fetal surgery for performing direct surgical procedures on fetuses with hysterotomy for LUTO [5], congenital pulmonary airway malformations (CPAM) [6], and congenital diaphragmatic hernia (CDH) [7]. In the 1990s, fetoscopic laser surgery (FLS) for twin-twin transfusion syn- drome (TTTS) was first performed, showing great success [8-11]. Open fetal surgery for CDH was changed to a fetoscopic procedure and established as fetoscopic endoluminal tracheal occlusion (FETO) in the 2000s $[12,13]$. The revival of open fetal surgery began in the 2010s after a successful clinical study for myelomeningocele (MMC) [14].

After 50 years, a number of fetal therapies are now being

Received: 2019.07.11. Revised: 2019.08.25. Accepted: 2019.09.09. Corresponding author: Haruhiko Sago, MD, PhD

Center for Maternal-Fetal, Neonatal and Reproductive Medicine, National Center for Child Health and Development, 2-10-1 Okura, Setagaya-ku, Tokyo, 157-8535 Japan

E-mail: sagou-h@ncchd.go.jp

https://orcid.org/0000-0001-9387-1849

Articles published in Obstet Gynecol Sci are open-access, distributed under the terms of the Creative Commons Attribution Non-Commercial License (http://creativecommons. org/licenses/by-nc/3.0/) which permits unrestricted non-commercial use, distribution, and reproduction in any medium, provided the original work is properly cited.

Copyright $\odot 2020$ Korean Society of Obstetrics and Gynecology 


\section{Obstetrics \& Gynecology Science}

Haruhiko Sago, et al. Standard fetal therapy

performed as clinically useful treatments, although others are still considered experimental treatments. Most achievements in fetal therapy have been made in the US and Western Europe [15]. We in Japan have contributed a bit through the promotion of fetal therapy in prenatal care in our country. Indeed, our findings have led three fetal therapies_FLS for TTTS [16], TAS for hydrothorax, and radiofrequency ablation (RFA) for twin reversed arterial perfusion (TRAP) sequenceto be approved for coverage by Japan National Health Insurance (Table 2). This means that these three fetal therapies are recognized as standard prenatal care, and fetuses are recognized as patients by the administration.

We herein review the present state of fetal therapy to highlight its role in perinatal medicine as standard prenatal care.

\section{Classification of fetal therapy}

Fetal therapy consists of medical therapy and surgical therapy, including percutaneous ultrasound-guided surgery, fetoscopic surgery, and open fetal surgery [17]. Medical fetal therapy involves the administration of medicine to the mother, where it is then transported to the fetus via the placenta or amniotic fluid. Fetal pharmacotherapy is used to manage arrhythmias, especially tachyarrhythmias, congenital adrenal hyperplasia and thyroid disorders [17]. Percutaneous ultrasound-guided surgery involves the insertion of a needle or catheter via the mother's abdomen into the fetus under ultrasound guidance. Percutaneous surgery includes shunt therapy for LUTO or hydrothorax, RFA for TRAP sequence, and intracardiac catheter procedures for aortic or pulmonary

Table 1. Milestones of surgical fetal therapy

\begin{tabular}{|c|c|c|}
\hline Percutaneous ultrasound-guided surgery & Fetoscopic surgery & Open fetal surgery \\
\hline \multicolumn{3}{|l|}{1981 Intrauterine blood transfusion } \\
\hline \multicolumn{3}{|l|}{1982 Vesico-amniotic shunting } \\
\hline & & 1983 Nephrostomy \\
\hline & & 1984 Resection of CPAM \\
\hline \multicolumn{3}{|l|}{1986 Thoraco-amniotic shunting } \\
\hline & & 1989 CDH repair \\
\hline & 1990 FLS (laparotomy) & \\
\hline \multicolumn{3}{|l|}{1991 Balloon dilation (aortic valve) } \\
\hline & 1993 Cord ligation for TRAP sequence & \\
\hline & 1995 FLS (percutaneous) & 1995 EXIT \\
\hline & 1997 FETENDO (CDH) & 1997 MMC repair \\
\hline & 2000 FETO & \\
\hline
\end{tabular}

2002 RFA for TRAP sequence

2004 Eurofetus trial for FLP

2011 MOMS trial for MMC

CPAM, congenital pulmonary airway malformation; CDH, congenital diaphragmatic hernia; EXIT, ex utero intrapartum treatment; FETENDO, fetal endoscopic surgery; FETO, fetoscopic endoluminal tracheal occlusion; FLS, fetoscopic laser surgery; MMC, myelomeningocele; MOMS, management of myelomeningocele study; RFA, radiofrequency ablation; TRAP, twin reversed arterial perfusion.

Table 2. Fetal therapies covered by Japan National Health Insurance

\begin{tabular}{llll}
\hline Disorder & \multicolumn{1}{c}{ Treatment } & Approval & References of our study \\
\hline Twin-twin transfusion syndrome & Fetoscopic laser surgery & April 2012 & Sago et al. [22] \\
Primary fetal hydrothorax & Thoraco-amniotic shunting & July 2012 & Takahashi et al. [43] \\
Twin reversed arterial perfusion sequence & Radiofrequency ablation & March 2019 & Sugibayashi et al. [56] \\
& & & Wagata et al. [57] \\
\hline
\end{tabular}




\title{
Obstetrics \& Gynecology Science
}

\author{
Vol. 63 , No. 2, 2020
}

valvuloplasty for stenosis. Fetoscopic surgery involves placing an endoscope in the amniotic fluid space for treatments. FLS uses a laser to coagulate the placental vessels, and FETO places a detachable balloon in the trachea of the fetus. Open fetal surgery is surgery performed directly on the fetus by laparotomy and hysterotomy, after which the hysterotomy is closed to keep the fetus in the uterus. Of note, it is associated with extensive morbidities for both the mother and the fetus. Most cases of open fetal surgery are performed for MMC.

\section{Assessment of fetal surgical therapy}

To assess the effectiveness of therapy, good-quality evidence is required. However, clear evidence in the field of fetal therapy is limited because of the rarity of the targeted diseases and difficulties enrolling unborn patients. Only three randomized control trials (RCTs) have suggested any benefits of fetal treatments thus far $[11,14,18]$. Two of these RCTs were for FLS, while the other was for open fetal surgery for MMC. We assessed the effectiveness of select fetal surgical therapies by scoring them $A A$ to $C$ ( $A A$ : effective according to RCT, A: effective, B: expected, C: unknown) based on previous reports and our own experience (Table 3). The availability of fetal therapy in Japan is also presented.

Percutaneous intracardiac catheter procedures for critical aortic stenosis, fetoscopic laser for LUTO, or open fetal surgery for MMC have not yet been performed in Japan, although we are preparing to perform them in the near future. The costs of three fetal therapies (FLS for TTTS, TAS for hydrothorax, and RFA for TRAP sequence) are compensated by Japan National Health Insurance. FLS for TTTS is the most common fetal therapy performed, followed by TAS for hydrothorax and RFA for TRAP sequence. These three minimally invasive fetal therapies constitute $85 \%$ of all treatments for fetuses performed at our center [16].

\section{Fetoscopic laser surgery}

TTTS, which occurs in one-tenth of monochorionic (MC) twin pregnancies, has high perinatal morbidity and mortality [19]. TTTS is diagnosed in cases of MC twin pregnancy complicated by polyhydramnios with a maximum vertical pocket
(MVP) $\geq 8.0 \mathrm{~cm}$ (with an enlarged bladder) in the recipient and oligohydramnios with an MVP $\leq 2.0 \mathrm{~cm}$ (with a small bladder) in the donor [20]. TTTS is considered to be a hemodynamic and likely hormonal disorder derived from a chronic blood flow imbalance between twins by vascular anastomoses on the placenta [21].

FLS, which ablates placental vascular anastomoses, is an effective treatment option for TTTS. The original technique of FLP was first reported by De Lia et al. with laparotomy [8] and advanced by Ville et al. as a percutaneous procedure under ultrasound guidance $[9,10]$. The RCT by the Eurofoetus group showed that FLS is more useful than serial amnioreduction [11]. FLS is widely accepted and performed as a standard treatment for TTTS around the world [16].

We started the FLS program in Japan in 2002. We reported our initial 181 cases of TTTS treated by FLS at 4 centers [22].

Table 3. Assessments of select fetal surgical therapies and their availability in Japan

\begin{tabular}{|c|c|c|}
\hline Therapy & Assessment & Availability \\
\hline \multicolumn{3}{|l|}{$\begin{array}{l}\text { Percutaneous ultrasound guided } \\
\text { surgery }\end{array}$} \\
\hline Intrauterine blood transfusion & A & Y \\
\hline \multicolumn{3}{|l|}{ Shunt } \\
\hline Lower urinary tract obstruction & B & Y \\
\hline Hydrothorax & $A$ & Y \\
\hline \multicolumn{3}{|l|}{ Radiofrequency ablation } \\
\hline $\begin{array}{l}\text { Twin reversed arterial perfusion } \\
\text { sequence }\end{array}$ & A & Y \\
\hline \multicolumn{3}{|l|}{ Intracardiac catheter } \\
\hline $\begin{array}{l}\text { Critical aortic stenosis, critical } \\
\text { pulmonary stenosis }\end{array}$ & C & Y \\
\hline \multicolumn{3}{|l|}{ Fetoscopic surgery } \\
\hline Fetoscopic laser surgery & AA & Y \\
\hline $\begin{array}{l}\text { Fetoscopic endoluminal tracheal } \\
\text { occlusion }\end{array}$ & B & Y \\
\hline $\begin{array}{l}\text { Cystoscopic laser for lower } \\
\text { urinary tract obstruction }\end{array}$ & C & $\mathrm{N}$ \\
\hline Myelomeningocele repair & C & $\mathrm{N}$ \\
\hline \multicolumn{3}{|l|}{ Open fetal surgery } \\
\hline Myelomeningocele repair & AA & $\mathrm{N}$ \\
\hline $\begin{array}{l}\text { Congenital pulmonary airway } \\
\text { malformation }\end{array}$ & C & $\mathrm{N}^{*}$ \\
\hline
\end{tabular}




\section{Obstetrics \& Gynecology Science}

Haruhiko Sago, et al. Standard fetal therapy

The mean gestational ages at FLS and delivery were around 21 and 33 weeks, respectively. The survival rates of both twins and at least 1 twin at 6 months of age were $62 \%$ and $90 \%$, respectively. Our findings led to recognition of FLS as the first-line treatment option for TTTS, and the costs of this procedure have been compensated by Japan National Health Insurance since April 2012 [16]. FLS was the first fetal

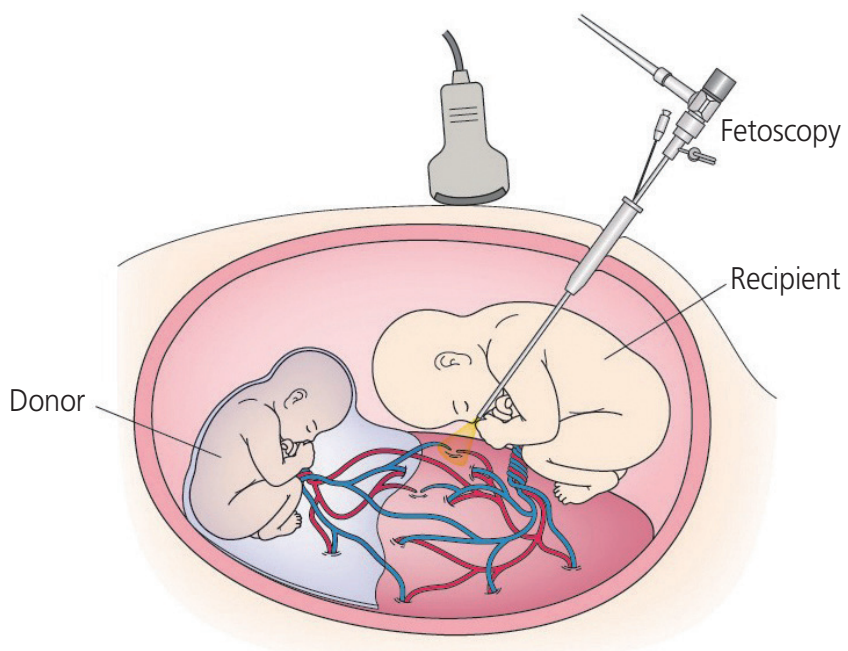

Fig. 1. A schematic representation of fetoscopic laser surgery for twin-twin transfusion syndrome. A fetoscope is percutaneously inserted into the recipient sac through a cannula. Placental vascular anastomoses between twins are ablated by a laser. therapy to be compensated by Japan National Health Insurance and is now established as a standard prenatal care procedure.

The procedure is illustrated in Fig. 1, and the details are described in our review [16]. A recent modified version of FLS, referred to as the 'Solomon technique,' adds ablation of the placenta to connect the anastomoses' coagulation sites in order to diminish residual anastomoses [18]. The perinatal outcomes after FLS improved significantly with advances in the technique and learning [23]. The recent survivals of both twins and at least one twin have been reported to be $70 \%$ and $>90 \%$, respectively [16]. However, despite this ameliorated survival rate, TTTS treated by FLS is still associated with neurodevelopmental impairments, including severe cerebral palsy and neurodevelopment delay. There is still about a $10 \%$ risk of long-term neurodevelopment impairment after FLS [16]. Improvement in the neurodevelopmental outcomes of twins treated with FLP is a future point of focus.

FLS is offered as the standard treatment option for TTTS at 16-26 weeks' gestation, which is considered to be the conventional indication $[11,16]$. Fetofetal transfusion syndrome (FFTS), which induces perinatal death and neurodevelopmental impairment, occurs in dichorionic triamniotic (DT) or monochorionic triamniotic (MT) triplets [24]. FFTS in triplets accords with TTTS in twins, so FLS is supposed to be a viable treatment option for FFTS in triplets. We and others

Table 4. Our criteria for performing fetoscopic laser surgery

\begin{tabular}{ll}
\hline Criteria & \multicolumn{1}{c}{ Description } \\
\hline Conventional criteria & Twin-twin transfusion syndrome at $16-26$ weeks \\
- Oligohydramnios with an MVP $\leq 2.0 \mathrm{~cm}$ in the donor \\
- Polyhydramnios with an MVP $\geq 8.0 \mathrm{~cm}$ in the recipient \\
- Gestational age between 16.0 and 25.6 weeks \\
1. Triplets \\
- Dichorionic triamniotic triplets or monochorionic triamniotic triplets \\
- Feto-fetal transfusion syndrome (MVP $\leq 2.0 \mathrm{~cm}$ in the donor and $\geq 8.0 \mathrm{~cm}$ in the recipient) \\
- Gestational age between 16.0 and 25.6 weeks \\
2. Twin-twin transfusion syndrome after 26 weeks \\
- Oligohydramnios with an MVP $\leq 2.0 \mathrm{~cm}$ in the donor \\
- Polyhydramnios with an MVP $\geq 10.0 \mathrm{~cm}$ in the recipient \\
- Gestational age between 26.0 and 27.6 weeks \\
3. Selective intrauterine growth restriction with oligohydramnios \\
- Estimated fetal weight $\leq-1.5 \mathrm{SD}$ or intertwin estimated fetal weight discordance $\geq 25 \%$ \\
- Absent or reverse end-diastolic velocity in the umbilical artery in the smaller twin \\
- Oligohydramnios with an MVP $\leq 2.0 \mathrm{~cm}$ in the smaller twin \\
- Gestational age between 16.0 and 25.6 weeks
\end{tabular}

MVP, maximum vertical pocket; SD, standard deviation. 


\title{
Obstetrics \& Gynecology Science
}

\author{
Vol. 63, No. 2, 2020
}

have shown that FLS is a useful therapy for FFTS in both DT and MT triplets $[25,26]$. The optimum gestational age for the therapy of TTTS was set at 16-26 weeks in the Eurofoetus multicenter randomized trial for FLS [11]; however, cases of TTTS after 26 weeks tend to demonstrate a high rate of morbidities despite receiving optimal management after birth. The accumulated results suggest that FLS could be a safe treatment option for TTTS after 26 weeks, especially at 26-28 weeks of gestation [27-29].

With the enhanced awareness of TTTS, more attention is now being paid to selective intrauterine growth restriction (sIUGR), a complicated MC twin pregnancy. sIUGR is diagnosed according to the difference in the fetal body weight of twins. Several studies have shown the application of FLS for sIUGR with absent or reverse end-diastolic velocity (AREDV) in the umbilical artery (UA) [30-32]. FLS may be a promising treatment option for sIUGR when accompanied by both AREDV in UA and severe oligohydramnios of IUGR twins $[33,34]$. Oligohydramnios in the IUGR twin may be an essential indication for FLP for SIUGR. The FLS criteria for nonconventional applications, including the treatment of triplets, TTTS after 26 weeks, and sIUGR, are shown in Table 4 [16]. FLS is the most successful and commonly performed fetal therapy at present and is recognized as a standard prenatal care approach, despite FLS only being available at select fetal treatment centers.

\section{Thoracoamniotic shunting}

Fetal hydrothorax (FHT) is a form of pleural effusion seen in fetuses. Primary FHT, called isolated FHT, is chylothorax due to lymphatic leakage. Secondary FHT is pleural fluid accumulation associated with fetal diseases, including fetal anemia, viral infection, and structural and chromosomal abnormalities [35-37]. The prognosis of secondary FHT relies on the primary etiology. The incidence of primary FHT is approximately $1 / 15,000$ [38]. Its natural history varies from spontaneous disappearance to the progressive aggregation of fluid and the occurrence of hydrops. Fetuses with primary FHT carry poor prognoses when they develop hydrops, which is thought to be a consequence of decreasing venous return to the heart affected by massive pleural effusion. TAS, which drains the pleural effusion, is a treatment option to improve the perinatal prognoses and has been reported to be associ- ated with a better outcome in severe primary FHT than no fetal intervention [39-41].

A "double-basket catheter" (Hakko Co., Nagano, Japan) was invented in Japan in the 1990s [42] and has since been frequently used for TAS in Japan. The procedure is illustrated in Fig. 2. We performed a prospective one-arm trial of TAS for isolated FHT using this very thin double-basket catheter [43]. The median gestational age at the procedure and delivery was about 27 and 35 weeks, respectively. The overall survival rate was $79 \%$, and the survival rate in the hydropic fetuses was $71 \%$. Drainage of fetal pleural effusions with a double-basket catheter was shown to be safe and effective. Our results led to the approval of the "double-basket catheter" as a medical device, and the costs of TAS have been compensated by Japan National Health Insurance since July 2012. TAS was the second fetal therapy to be compensated by Japan National Health Insurance and is now established as a standard prenatal care approach.

We conducted a nationwide survey on fetuses with primary FHT delivered after 22 weeks' gestation at January 2007 to December 2011 [44]. The survivals for primary FHT with and without hydrops were $58 \%$ and $98 \%$, respectively. A lower gestational age at the diagnosis, severe hydrops and severe pleural effusion were predicting factors of poor prognoses. TAS was associated with a significant reduction in the risk

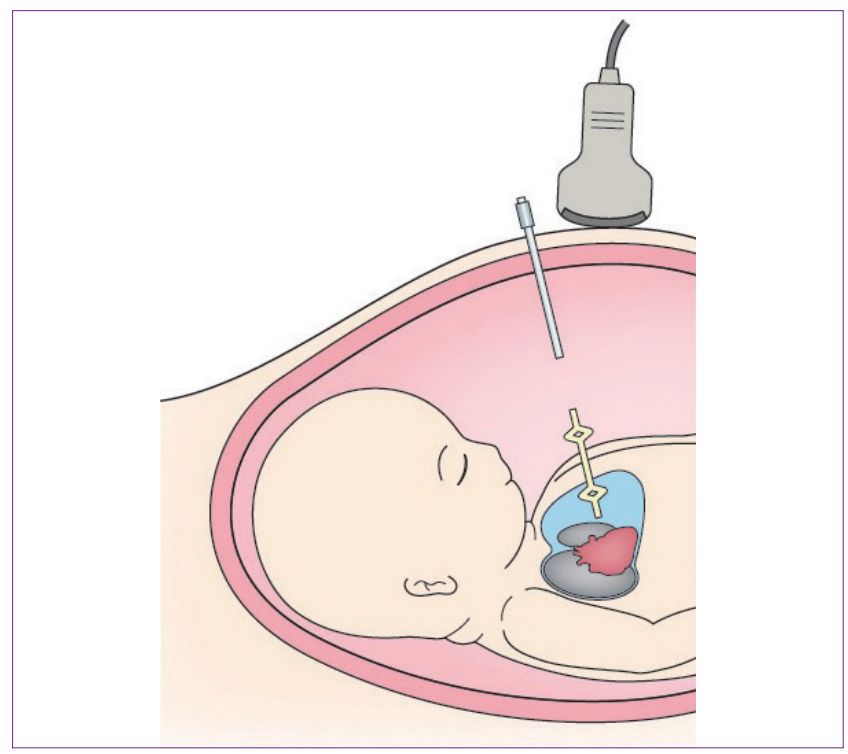

Fig. 2. A schematic representation of thoracoamniotic shunting for fetal hydrothorax. A double-basket catheter is placed in the chest to drain the pleural effusion into the amniotic fluid. 


\section{Obstetrics \& Gynecology Science}

Haruhiko Sago, et al. Standard fetal therapy

of death in hydropic cases. Down syndrome, or trisomy 21, is frequently associated with FHT. The prognosis of FHT with trisomy 21 is not very bad but is still poorer than that of primary FHT [45]. Fetal therapy is thought to provide no benefits for FHT with trisomy 21 [45].

\section{Radiofrequency ablation}

An acardiac twin is an uncommon complicated monochorionic twin pregnancy occurring in $1 \%$ of $M C$ twins [46]. The acardiac twin's blood is circulated by the pump twin through arterioarterial and venovenous anastomoses on the placenta. The perinatal outcome is particularly poor in cases with continuing reversed arterial flow, called TRAP sequence, as the pump twin develops high-output cardiac failure, leading to fetal hydrops and/or intrauterine fetal death (IUFD) or preterm birth due to polyhydramnios [47]. Various fetal therapies for interrupting the perfusion of the acardiac twin have been undertaken. These procedures include extrafetal treatment, such as monopolar or bipolar cord coagulation $[48,49]$, and intrafetal treatment, such as laser ablation [50] and RFA [51], which are minimally invasive techniques.

RFA induces coagulation of tissue by delivering high temperatures through a high-frequency alternating current. The first case of TRAP sequence treatment using RFA was shown by the University of California at San Francisco [52]. RFA uses a 17-gauge needle electrode guided by ultrasound. The procedure is illustrated in Fig. 3. RFA has a lower risk of premature preterm rupture of membranes than extrafetal methods $[53,54]$. Lee et al. [55] reported the North American Fetal Therapy Network registry data of RFA treatment for TRAP sequence and showed the $80 \%$ survival rate. Two studies of RFA for TRAP sequence were performed in Japan $[56,57]$. We reported the outcomes of 40 cases of TRAP sequence treated with RFA, which is the largest single-center study [56]. The overall survival rate was $85 \%$, and the mean gestational age at delivery was 37 weeks for the pump twins. The other study also reported good outcomes of RFA treatment for TRAP sequence, with a survival rate of $88 \%$ [57]. Although reports of RFA treatment for TRAP sequence are limited, RFA is thought to be a useful treatment option for TRAP sequence after 15 weeks' gestation. Our results led to the approval of a medical device application for RFA, and the costs of RFA are now compensated by Japan National Health
Insurance as of March 2019. RFA for TRAP sequence is the third fetal therapy to be compensated by Japan National Health Insurance and is considered a standard prenatal care approach for TRAP sequence.

\section{Conclusion}

More than 50 years have passed since the first attempt to treat a fetus in utero. However, while various efforts have been made, many fetal therapies are still considered experimental. Nevertheless, some fetal therapies are now accepted as effective treatments options, including FLS for TTTS, TAS for primary FHT, and RFA for TRAP sequence. These 3 fetal therapies have been approved for coverage by Japan National Health Insurance based on the results of clinical studies performed in Japan. FLS for TTTS, TAS for primary FHT, and RFA for TRAP sequence are all minimally invasive fetal therapies that have become standard prenatal care approaches in Japan. These 3 fetal therapies will help improve the perinatal

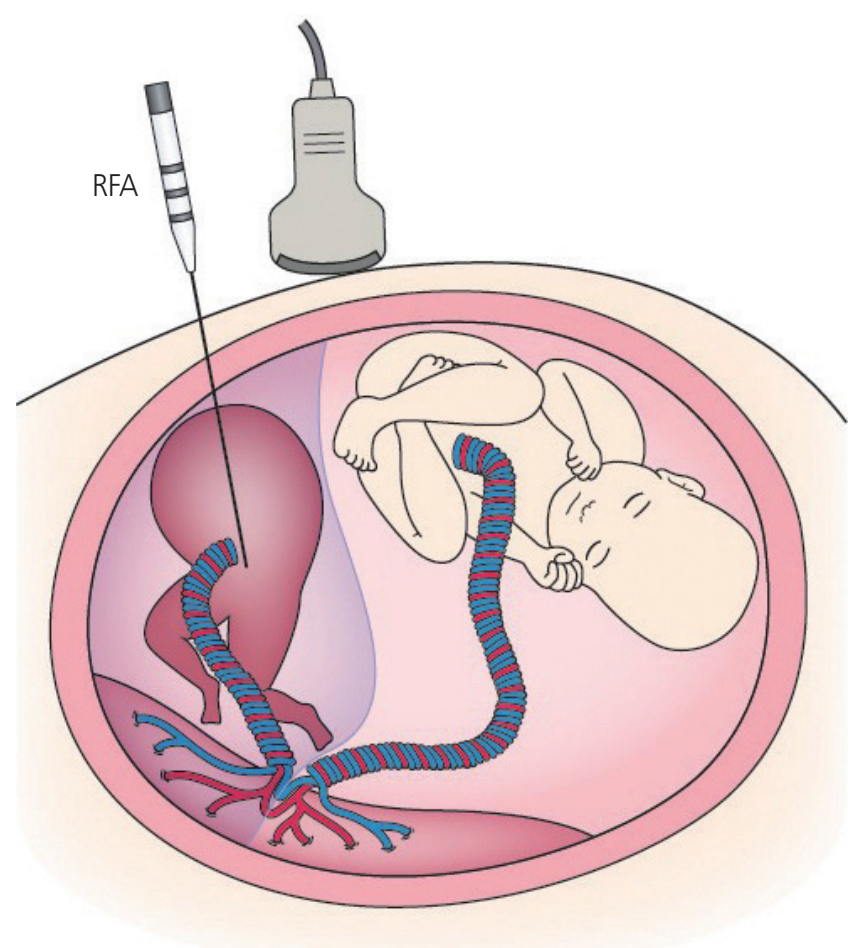

Fig. 3. A schematic representation of radiofrequency ablation (RFA) for twin reversed arterial perfusion sequence. A needle electrode is inserted into the acardiac twin to coagulate the body part, and then the blood flow is discontinued. 


\section{Obstetrics \& Gynecology Science}

Vol. 63, No. 2, 2020

outcomes of fetuses with these diseases. The goal of fetal therapy is to ensure the survival of fetuses without complications. Well-designed studies and cautious preparations are essential for effectively promoting fetal therapy.

\section{Acknowledgements}

This work was supported by a grant from The National Center for Child Health and Development, Tokyo, Japan (305). We thank Drs. K. Ozawa, R. Sugibayashi, and J. Muromoto for their co-operation in promoting the fetal therapy program at our center. We thank Drs. T. Murakoshi (Seirei Hamamatsu General Hospital), M. Nakata (Toho University), J. Murotsuki (Miyagi Children's Hospital), K. Ishii, (Osaka Women's and Children's Hospital), Y. Takahashi (Nagara Medical Center), and M. Endo (Osaka University) for their long-term co-operation in the research and practice of fetal intervention as members of the Japan Fetal Therapy Group.

\section{Conflict of interest}

No potential conflict of interest relevant to this article was reported.

\section{References}

1. Liley AW. Intrauterine transfusion of foetus in haemolytic disease. BMJ 1963;2:1107-9.

2. Bang J, Bock JE, Trolle D. Ultrasound-guided fetal intravenous transfusion for severe rhesus haemolytic disease. Br Med J (Clin Res Ed) 1982;284:373-4.

3. Golbus MS, Harrison MR, Filly RA, Callen PW, Katz M. In utero treatment of urinary tract obstruction. Am J Obstet Gynecol 1982;142:383-8.

4. Rodeck $\mathrm{CH}$, Fisk NM, Fraser DI, Nicolini U. Long-term in utero drainage of fetal hydrothorax. N Engl J Med 1988;319:1135-8.

5. Crombleholme TM, Harrison MR, Langer JC, Longaker MT, Anderson RL, Slotnick NS, et al. Early experience with open fetal surgery for congenital hydronephrosis. J Pediatr Surg 1988;23:1114-21.

6. Adzick NS, Harrison MR, Flake AW, Howell LJ, Golbus
MS, Filly RA. Fetal surgery for cystic adenomatoid malformation of the lung. J Pediatr Surg 1993;28:806-12.

7. Harrison MR, Adzick NS, Longaker MT, Goldberg JD, Rosen MA, Filly RA, et al. Successful repair in utero of a fetal diaphragmatic hernia after removal of herniated viscera from the left thorax. N Engl J Med 1990;322:1582-4.

8. De Lia JE, Cruikshank DP, Keye WR Jr. Fetoscopic neodymium:YAG laser occlusion of placental vessels in severe twin-twin transfusion syndrome. Obstet Gynecol 1990;75:1046-53.

9. Ville $Y$, Hyett J, Hecher K, Nicolaides K. Preliminary experience with endoscopic laser surgery for severe twin-twin transfusion syndrome. N Engl J Med 1995;332:224-7.

10. Ville Y, Hecher K, Gagnon A, Sebire N, Hyett J, Nicolaides $\mathrm{K}$. Endoscopic laser coagulation in the management of severe twin-to-twin transfusion syndrome. $\mathrm{Br} J$ Obstet Gynaecol 1998;105:446-53.

11. Senat MV, Deprest J, Boulvain M, Paupe A, Winer N, Ville $Y$. Endoscopic laser surgery versus serial amnioreduction for severe twin-to-twin transfusion syndrome. N Engl J Med 2004;351:136-44.

12. Harrison MR, Keller RL, Hawgood SB, Kitterman JA, Sandberg $\mathrm{PL}$, Farmer $\mathrm{DL}$, et al. A randomized trial of fetal endoscopic tracheal occlusion for severe fetal congenital diaphragmatic hernia. N Engl J Med 2003;349:1916-24.

13. Deprest J, Gratacos E, Nicolaides KH; FETO Task Group. Fetoscopic tracheal occlusion (FETO) for severe congenital diaphragmatic hernia: evolution of a technique and preliminary results. Ultrasound Obstet Gynecol 2004;24:121-6.

14. Adzick NS, Thom EA, Spong CY, Brock JW 3rd, Burrows $\mathrm{PK}$, Johnson MP, et al. A randomized trial of prenatal versus postnatal repair of myelomeningocele. $\mathrm{N}$ Engl J Med 2011;364:993-1004.

15. Deprest JA, Flake AW, Gratacos E, Ville Y, Hecher K, Nicolaides $K$, et al. The making of fetal surgery. Prenat Diagn 2010;30:653-67.

16. Sago H, Ishii K, Sugibayashi R, Ozawa K, Sumie M, Wada $S$. Fetoscopic laser photocoagulation for twintwin transfusion syndrome. J Obstet Gynaecol Res 2018;44:831-9.

17. Fetal therapy. In: Cunningham FG, Leveno KJ, Bloom SL, Dashe JS, Hoffman BL, Casey BM, et al., editors, Wil- 


\title{
Obstetrics \& Gynecology Science
}

\author{
Haruhiko Sago, et al. Standard fetal therapy
}

liams obstetrics. 25th ed. New York (NY): McGraw-Hill Education; 2018. p. 315-30.

18. Slaghekke F, Lopriore E, Lewi L, Middeldorp JM, van Zwet EW, Weingertner AS, et al. Fetoscopic laser coagulation of the vascular equator versus selective coagulation for twin-to-twin transfusion syndrome: an open-label randomised controlled trial. Lancet 2014;383:2144-51.

19. Mahony BS, Petty CN, Nyberg DA, Luthy DA, Hickok DE, Hirsch JH. The "stuck twin" phenomenon: ultrasonographic findings, pregnancy outcome, and management with serial amniocenteses. Am J Obstet Gynecol 1990;163:1513-22.

20. Quintero RA, Morales WJ, Allen MH, Bornick PW, Johnson PK, Kruger M. Staging of twin-twin transfusion syndrome. J Perinatol 1999;19:550-5.

21. Diehl W, Hecher K, Zikulnig L, Vetter M, Hackelöer BJ. Placental vascular anastomoses visualized during fetoscopic laser surgery in severe mid-trimester twin-twin transfusion syndrome. Placenta 2001;22:876-81.

22. Sago $H$, Hayashi $S$, Saito $M$, Hasegawa $H$, Kawamoto $\mathrm{H}$, Kato $\mathrm{N}$, et al. The outcome and prognostic factors of twin-twin transfusion syndrome following fetoscopic laser surgery. Prenat Diagn 2010;30:1185-91.

23. Diehl W, Diemert A, Grasso D, Sehner S, Wegscheider K, Hecher K. Fetoscopic laser coagulation in 1020 pregnancies with twin-twin transfusion syndrome demonstrates improvement in double-twin survival rate. Ultrasound Obstet Gynecol 2017;50:728-35.

24. Sato Y, Ishii K, Yokouchi T, Murakoshi T, Kiyoshi K, Nakayama $S$, et al. Incidences of feto-fetal transfusion syndrome and perinatal outcomes in triplet gestations with monochorionic placentation. Fetal Diagn Ther 2016;40:181-6.

25. Sepulveda W, Surerus E, Vandecruys $H$, Nicolaides KH. Fetofetal transfusion syndrome in triplet pregnancies: outcome after endoscopic laser surgery. Am J Obstet Gynecol 2005;192:161-4.

26. Ishii K, Nakata M, Wada S, Hayashi S, Murakoshi T, Sago $\mathrm{H}$. Perinatal outcome after laser surgery for triplet gestations with feto-fetal transfusion syndrome. Prenat Diagn 2014;34:734-8.

27. Valsky DV, Eixarch E, Martinez-Crespo JM, Acosta ER, Lewi L, Deprest J, et al. Fetoscopic laser surgery for twinto-twin transfusion syndrome after 26 weeks of gestation. Fetal Diagn Ther 2012;31:30-4.
28. Baud D, Windrim R, Keunen J, Kelly EN, Shah P, van Mieghem $T$, et al. Fetoscopic laser therapy for twin-twin transfusion syndrome before 17 and after 26 weeks' gestation. Am J Obstet Gynecol 2013;208:197.e1-7.

29. Nakata M, Ishii K, Sumie M, Takano M, Hirata H, Murata $S$, et al. A prospective pilot study of fetoscopic laser surgery for twin-to-twin transfusion syndrome between 26 and 27 weeks of gestation. Taiwan J Obstet Gynecol 2016;55:512-4.

30. Quintero RA, Bornick PW, Morales WJ, Allen MH. Selective photocoagulation of communicating vessels in the treatment of monochorionic twins with selective growth retardation. Am J Obstet Gynecol 2001;185:689-96.

31. Gratacós E, Antolin E, Lewi L, Martínez JM, HernandezAndrade $E$, Acosta-Rojas $R$, et al. Monochorionic twins with selective intrauterine growth restriction and intermittent absent or reversed end-diastolic flow (Type III): feasibility and perinatal outcome of fetoscopic placental laser coagulation. Ultrasound Obstet Gynecol 2008;31:669-75.

32. Chalouhi GE, Marangoni MA, Quibel T, Deloison B, Benzina $\mathrm{N}$, Essaoui $\mathrm{M}$, et al. Active management of selective intrauterine growth restriction with abnormal Doppler in monochorionic diamniotic twin pregnancies diagnosed in the second trimester of pregnancy. Prenat Diagn 2013;33:109-15.

33. Ishii K, Nakata M, Wada S, Murakoshi T, Sago H. Feasibility and preliminary outcomes of fetoscopic laser photocoagulation for monochorionic twin gestation with selective intrauterine growth restriction accompanied by severe oligohydramnios. J Obstet Gynaecol Res 2015;41:1732-7.

34. Ishii K, Wada S, Takano M, Nakata M, Murakoshi T, Sago $\mathrm{H}$. Survival rate without brain abnormalities on postnatal ultrasonography among monochorionic twins after fetoscopic laser photocoagulation for selective intrauterine growth restriction with concomitant oligohydramnios. Fetal Diagn Ther 2019;45:21-7.

35. Smith RP, Illanes S, Denbow ML, Soothill PW. Outcome of fetal pleural effusions treated by thoracoamniotic shunting. Ultrasound Obstet Gynecol 2005;26:63-6.

36. Achiron R, Weissman A, Lipitz S, Mashiach S, Goldman B. Fetal pleural effusion: the risk of fetal trisomy. Gynecol Obstet Invest 1995;39:153-6.

37. Barron SD, Pass RF. Infectious causes of hydrops fetalis. 


\section{Obstetrics \& Gynecology Science}

Vol. 63, No. 2, 2020

Semin Perinatol 1995;19:493-501.

38. Longaker MT, Laberge JM, Dansereau J, Langer JC, Crombleholme TM, Callen PW, et al. Primary fetal hydrothorax: natural history and management. J Pediatr Surg 1989;24:573-6.

39. Weber AM, Philipson EH. Fetal pleural effusion: a review and meta-analysis for prognostic indicators. Obstet Gynecol 1992;79:281-6.

40. Yinon Y, Grisaru-Granovsky S, Chaddha V, Windrim R, Seaward PG, Kelly EN, et al. Perinatal outcome following fetal chest shunt insertion for pleural effusion. Ultrasound Obstet Gynecol 2010;36:58-64.

41. Jeong BD, Won HS, Lee MY, Shim JY, Lee PR, Kim A. Perinatal outcomes of fetal pleural effusion following thoracoamniotic shunting. Prenat Diagn 2015;35:1365-70.

42. Chiba Y, Kobayashi H, Kanzaki T, Murakami M, Takahashi S, Takahashi H. Clinical aspects of fetal obstructive uropathy with in utero estimation of renal function and intrauterine shunt placement. J Matern Fetal Investig 1993;3:225-31.

43. Takahashi Y, Kawabata I, Sumie M, Nakata M, Ishii K, Murakoshi T, et al. Thoracoamniotic shunting for fetal pleural effusions using a double-basket shunt. Prenat Diagn 2012;32:1282-7.

44. Wada S, Jwa SC, Yumoto Y, Takahashi Y, Ishii K, Usui N, et al. The prognostic factors and outcomes of primary fetal hydrothorax with the effects of fetal intervention. Prenat Diagn 2017;37:184-92.

45. Yumoto Y, Jwa SC, Wada S, Takahashi Y, Ishii K, Kato $K$, et al. The outcomes and prognostic factors of fetal hydrothorax associated with trisomy 21. Prenat Diagn 2017;37:686-92.

46. Gillim DL, Hendricks CH. Holoacardius; review of the literature and case report. Obstet Gynecol 1953;2:647-53.

47. Moore TR, Gale S, Benirschke K. Perinatal outcome of forty-nine pregnancies complicated by acardiac twinning. Am J Obstet Gynecol 1990;163:907-12.

48. Lewi L, Gratacos E, Ortibus E, Van Schoubroeck D, Carreras $E$, Higueras $T$, et al. Pregnancy and infant outcome of 80 consecutive cord coagulations in complicated monochorionic multiple pregnancies. Am J Obstet Gynecol 2006;194:782-9.

49. Lanna MM, Rustico MA, Dell'Avanzo M, Schena V,
Faiola S, Consonni D, et al. Bipolar cord coagulation for selective feticide in complicated monochorionic twin pregnancies: 118 consecutive cases at a single center. Ultrasound Obstet Gynecol 2012;39:407-13.

50. Scheier M, Molina FS. Outcome of twin reversed arterial perfusion sequence following treatment with interstitial laser: a retrospective study. Fetal Diagn Ther 2012;31:35-41.

51. Chaveeva P, Poon LC, Sotiriadis A, Kosinski P, Nicolaides $\mathrm{KH}$. Optimal method and timing of intrauterine intervention in twin reversed arterial perfusion sequence: case study and meta-analysis. Fetal Diagn Ther 2014;35:267-79.

52. Tsao K, Feldstein VA, Albanese CT, Sandberg PL, Lee $H$, Harrison MR, et al. Selective reduction of acardiac twin by radiofrequency ablation. Am J Obstet Gynecol 2002;187:635-40.

53. Gaerty K, Greer RM, Kumar S. Systematic review and metaanalysis of perinatal outcomes after radiofrequency ablation and bipolar cord occlusion in monochorionic pregnancies. Am J Obstet Gynecol 2015;213:637-43.

54. Bebbington MW, Danzer E, Moldenhauer J, Khalek N, Johnson MP. Radiofrequency ablation vs bipolar umbilical cord coagulation in the management of complicated monochorionic pregnancies. Ultrasound Obstet Gynecol 2012;40:319-24.

55. Lee $H$, Bebbington $M$, Crombleholme TM; North American Fetal Therapy Network. The North American Fetal Therapy Network Registry data on outcomes of radiofrequency ablation for twin-reversed arterial perfusion sequence. Fetal Diagn Ther 2013;33:224-9.

56. Sugibayashi R, Ozawa K, Sumie M, Wada S, Ito Y, Sago H. Forty cases of twin reversed arterial perfusion sequence treated with radio frequency ablation using the multistep coagulation method: a single-center experience. Prenat Diagn 2016;36:437-43.

57. Wagata M, Murakoshi T, Ishii K, Muromoto J, Sasahara J, Murotsuki J. Radiofrequency ablation with an internally cooled electrode for twin reversed arterial perfusion sequence. Fetal Diagn Ther 2016;40:110-5.

58. Kitano Y, Chiba T, Kuroda T, Sago H, Hayashi S, Kitagawa $\mathrm{M}$, et al. Open fetal surgery for congenital cystic adenomatoid malformation complicated with fetal hydrops: A case report. J Jpn Soc Perin Neon Med 2005;41:67-72. 